\title{
The Affect of Innovation Strategies and their Connect to Company Performance
}

\author{
Prof Theuns Pelser \\ North-West University \\ E-mail: theuns.pelser@nwu.ac.za
}

\section{Doi:10.5901/mjss.2014.v5n9p60}

\section{Abstract}

The management of innovation is made difficult by the complexity, unpredictability and pace of turbulence in the environment which compresses the time horizons for strategic planning and increases the investment risk The main purpose of this study was to investigate innovation management practices in technology intensive industries and to explore their relationship to company performance. A non-probability, judgment sample of companies listed on the Johannesburg Stock Exchange (JSE) were taken. The study makes a contribution to the field of strategic management research by integrating the dimensions of several previous studies, to derive a more comprehensive taxonomy of innovation strategy dimensions. Two distinct innovation strategy factors obtained with the analysis were proved to positively influence the company performance dimensions and were classified as New Product Innovation and Process Innovation factors. The results show that innovation strategy choices can significantly affect company performance. It thereby indicates which of the underlying dimensions have the strongest relationship with company performance. From an industry perspective, the greatest significance of these findings may be that they accentuate the importance of innovation policy in strategic management. The substantial differences in performance associated with the dimensions do not necessarily indicate that a given company should choose a particular innovation strategy, but rather indicates that innovation policy decisions may have a substantial leverage on a company's performance and should be analysed and exercised with care.

Keywords: company performance; innovation policy; new product innovation; process innovation.

\section{Introduction}

The ability of discontinuous technological innovations to change the rules of competition, even eliminate the boundaries between industries, can have an enormous impact on the performance and survivability of companies. It is, therefore, imperative for companies to be able to adapt and evolve if they wish to survive. International business literature suggests that companies develop competitive advantages in order to ensure success in current markets (Hamel \& Prahalad, 2006; Levitt, 1983; Ohmae, 1989; Panagiotou, 2007; Pérez-Luño \& Cambra, 2013).

In order to acquire advantages, companies may develop technical knowledge from internal and/or external sources. Experience curve advantage may, therefore, be developed by companies that can successfully accumulate integrated knowledge in their business operations. Studies (e.g. by Pérez-Luñoa et al., 2011), have shown that one of the important factors for successful innovation, is good coupling among design, development, production and marketing functions. Companies that fail to synthesise these functional activities, could result in business collapse (Ohmae, 1989). The importance of learning from technology has been emphasised by Freeman (1994). But, technical knowledge can hardly be obtained without the necessary processing and modification. Mature companies, especially, have difficulty adapting to changes in technology (Hamel \& Prahalad, 2006).

In coming years, the widely acknowledged importance of technology will grow, increasing the wager executives must place on their companies' ability to compete through technology (Shoham \& Fiegenbaum, 2002). The cutting edge of technology management, however, goes beyond basic research and development (R\&D) expenditures. Increasingly, corporate strategists are making a more precise distinction between "technology" and "technology management." Technology addresses the application of scientific and engineering knowledge to the solution of problems. Technology management, however, has a broader charter as it is the integration of technology throughout the organisation as a source of sustainable competitive advantage (Harmon \& Davenport, 2007).

\section{Background}

Some management scientists believe that innovation is one of the principal methods through which organisations could 
adapt to and manage their environments (Dahan \& Shoham, 2014). Research has shown that industry leaders are noticeably more innovative than their competitors and those innovative companies are more successful in terms of turnover and profits (Pérez-Luño \& Cambra, 2013). Further, it has been suggested, that innovation creates competitive advantage and that a continuous stream of innovations is a vital component of long-term survival (Dahan \& Shoham, 2014; Hamel \& Prahlad, 2006).

An increasing number of management scientists believe, that in addition to short-term profits, top management has the responsibility to create a strategic capacity for continuous renewal within the organisation. Renewing the company's strategic potential and, in fact, long-term survival, means that significant resources should be allocated to the strategic processes of envisioning the future, imagining what could be and creating new competitive spaces. Innovation is a significant component in achieving these objectives (Hamel \& Prahlad, 2006).

\subsection{Innovation strategy dimensions}

When an attempt is made to define terms such as new, creativity or discovery, it often results in a game of semantics. First, what is new to one company may be old to another. Second, is success determined in terms of commercial gain or in terms of scientific achievement? Third, it is context dependent - what is viewed as a success today may be viewed as a failure in the future (Garnett \& Pelser, 2007).

The terms "creativity" and "innovation" are often used interchangeably in research studies, and the distinction between the two concepts may be more one of emphasis than of substance (Song et al., 2013). Nonetheless, some agreement about the terms' definitions has emerged recently; creativity has to do with the creation of novel and useful ideas (Ensminger et al., 2004), while innovation relates to the creation or adoption of useful ideas and idea implementation (Hung-Chia, 2013).

The conception of new ideas is the starting point for innovation. A new idea by itself, while interesting, is neither an invention nor an innovation; it is merely a concept that is novel with respect to some frame of reference, e.g. individual, departmental, organisational, or all accumulated knowledge. The process of converting intellectual thoughts into reality (usually a product or process) is an invention (Hung-Chia, 2013). This is where science and technology usually play a significant role. At this stage inventions need to be converted into products that will improve company performance. Therefore, exploitation normally implies wide acceptance and/or profitability resulting from the invention (Dahan \& Shoham, 2014).

Innovation policies encompass both the contents of innovation strategies and the processes of innovation management. The seminal work from Rothwell (1992) provides an extensive synopsis of key factors that appear to emerge in many studies, in relation to companies that are technically progressive or associated with successful innovation. Pelser (2001) synthezide these factors in the following innovation strategy dimensions:

- Product Innovation

- Process Innovation

- Marketing Innovation

- Management Innovation

According to Rothwell (1992), these key set of factors underpin successful innovations. This introduces the notion, that innovation is a process with a number of distinctive features that have to be managed (Rauch et al., 2009).

\subsection{Company performance}

Zahra \& Hayton (2008) established that the literature on performance is very extensive, but that it shows a lack of consensus as to the meaning of the term. Brush \& Vanderwerf (1992) point out, that the use of the term "performance" by researchers includes many constructs measuring alternative aspects of performance. This is consistent with the finding of Murphy et al. (1996) who, after a comprehensive literature review, were able to isolate a total of 71 different measures of performance. In spite of this apparent abundance, the vast majority of studies have used financial measures of performance (Hansen, 2010).

The raison d'être for this fixation with financial performance measures, is found partly in the fact that financial performance is at the core of the organisational control systems and partly in that it is one of the most easily quantifiable measuring instruments. However, this has caused empirical research to rely on a narrow set of accounting measures of financial performance, such as return on investment (ROI), return on assets (ROA), or earnings per share (Pandian, et al., 2006; Sapienca et al., 1988). 
The innovation management organisation (IMO) is responsible for developing new products and technologies (Pérez-Luñoa et al., 2011). Science and technology from the external environment are combined with the company's inhouse skills, knowledge and competencies to develop new products and technologies. The responsibilities that fall within the domain of innovation management encompass research and development (R\&D). For this reason, R\&D consists of those activities and responsibilities ranging from understanding progressive technology to generating ideas to developing new products and technologies.

Understanding the dynamics of the innovation management organisation (IMO) is important to understanding the role and impact of strategic leadership of innovation in technology intensive companies. The conceptual definition is, therefore, the extent to which the R\&D manager or other top manager perceives that the IMO has achieved its desired objectives over the last three years.

\section{Problem Statement and Research Hypotheses}

The main purpose of this study was to investigate innovation strategies in widespread use in technology intensive industries and to explore their relationship to company performance. Based on the literature review and arguments made, this study proposed the following hypotheses:

H1. New Product Innovation has a positive impact on company performance.

H2. Process Innovation has a positive impact on company performance.

\section{Research Methodology}

\subsection{Data requirements}

The innovation strategy dimensions pertaining to this study were synthesised into the following four dimensions (Pelser, 2001):

1. Product Innovation is the commercialisation of a new product. It is measured in terms of the emphasis a company places on a stated and working strategy of product innovation and the way it evaluates product innovation's performance relative to objectives:

- Have a stated and working strategy of product innovation.

- Evaluate product innovation's performance relative to objectives.

2. Process Innovation refers to innovation in technologies, techniques, systems and procedures that are involved in transforming inputs into outputs. It is measured in terms of the emphasis a company places on a stated and working strategy of process innovation and the way it evaluates process innovation's performance relative to objectives:

- Have a stated and working strategy of process innovation.

- Evaluate process innovation's performance relative to objectives.

3. Marketing Innovation refers to innovation in marketing activities that are involved in integrating the customer needs with the company's profit needs. It is measured in terms of the emphasis a company places on a stated and working strategy of marketing innovation and the way it evaluates marketing innovation's performance relative to objectives:

- Have a stated and working strategy of marketing innovation.

- Evaluate marketing innovation's performance relative to objectives.

4. Management Innovation refers to innovation in management activities and key responsibilities for utilising available resources to strategically position the company in the environment to meet its goals and objectives. It is measured in terms of the emphasis placed on a stated and working strategy of management innovation and the way management evaluates innovation's performance relative to objectives:

- Have a stated and working strategy of management innovation.

- Evaluate management innovation's performance relative to objectives.

Each dimension measured through the use of two items in the questionnaire. The questionnaire items were designed to permit answers on a five-point interval or Likert Scale. A survey questionnaire was developed and tested in a small pilot study in order to assess the clarity of the directions and questionnaire items. It was then revised and submitted to five technology strategists to confirm its intelligibility and cognitively confirm the validity of the study dimensions and variables as relating to important factors in strategic management of technology. 
The selection of the company performance dimensions resulted in six dependent variables. These six variables were classified in the following two dimension groups:

- Effectiveness of the IMO - (4 input dependent variables).

- Performance of the company - (2 output dependent variables).

The measures selected for this study, demonstrate strong relationships with company performance and had been reviewed in the literature section:

1. Contribution to sales (i.e. right product at the right time).

2. Efficiency of innovation project management (i.e. project success rate).

3. Impact of the innovations (e.g. degree of novelty or technical impact).

4. $R \& D$ expenditure (i.e. investment in $R \& D$ activities).

5. Patent information (i.e. output of R\&D activities).

6. Return on assets (i.e. company financial performance).

Factor analysis was used to reduce the dimensions into identifiable factors. Pearson r-correlation was then used to find the strength and direction of the relationships between the factors and the performance dimensions. The relationships examined, are those between the independent variables and the effectiveness of the innovation management organisation (IMO) and the performance of the company.

\subsection{Sample selection}

A non-probability, judgment sample of companies listed on the Johannesburg Stock Exchange (JSE) was taken. It was decided to use listed companies on the JSE for two primary reasons: (1) Listed companies display a capacity and capability (capital and human resources) for R\&D activities compared to smaller unlisted companies. (2) Quantifiable data (e.g. annual reports) is more readily available for the external stakeholders of listed companies than it is on unlisted companies. Based on the abovementioned screening criteria, it was decided to use the Industrial Consumer sector.

Two hundred companies or divisions were identified and incorporated in the survey after the screening stage. Feedback was received from 89 R\&D managers of these two hundred companies, stating their willingness to participate in the survey. A total of 84 completed responses were received and captured for the study. This translates to a 42 percent response rate from the base of 200 originally identified companies. However, compared to the feedback received from the 89 respondents, it effectively means, that the filtered response rate equates to 94 percent.

The non-response portion of the original sample of 200 companies is comprised of 64 companies. An additional 24 companies have indicated that they are not involved in any type of R\&D activities, which automatically excluded them from the study. Another 23 companies provided feedback or reasons concerning their non-participation in the survey, which ranges from vacant positions in R\&D key functions to a lack of interest of these type of research efforts.

\section{Analysis of Results}

\subsection{Factor analysis: innovation strategy}

The eight innovation strategy variables (A13 - A20) were factor-analysed by using the principal axis factoring method. Then using the latent root criterion, two factors were extracted on the basis of their Eigenvalues being greater than 1. Together they accounted for 82.61 percent of the variation in the data. The factors were rotated by using the Varimax rotation method. All the variables had correlations greater than .41 and more than 90 percent of the matrix elements were greater than .50. Bartlett's test of sphericity confirmed, that the correlation matrix was not an identity matrix. The KaiserMeyer-Olsen (KMO) measure as sampling adequacy, was .770, which Hair et al. (2010) characterised as "middling". This is also defined as an adequate measure, indicating that the degree of correlation between the unique factors was low. The anti-image covariance matrix contained few elements with values greater than 0.9 , again confirming the applicability of factor analysis. The number of factors to be extracted was set at two, based on the Kaiser criterion of selecting factors with Eigenvalues greater than 1.

The Chi-square statistic was 754.074 with 28 degrees of freedom, which is significant at the .000 level. The reduced set of variables collectively meets the necessary threshold of sampling adequacy and thus the fundamental requirements for factor analysis. The final statistics show, that 82.61 percent of the variance was explained by the two factors. The reproduced correlation contained 10 residual values (35 percent) greater than .05 indicating that the model fits the data.

The rotated innovation strategy factor loadings are contained in Table 1. As a reminder, each survey respondent 
was asked to report on the importance of each of the variables to his or her company relative to major competitors. The heaviest factor loading for each variable is formatted in bold font style.

Table 1. Rotated innovation strategy factor matrix

\begin{tabular}{|clcc|}
\hline Variable & \multicolumn{1}{c}{ Variable Description } & Factor 1 & Factor 2 \\
\hline A20 & Evaluate management innovation's performance & .874 & .179 \\
A19 & Have a strategy of management innovation & .851 & .300 \\
A17 & Have a strategy of marketing innovation & .817 & .324 \\
A18 & Evaluate marketing innovation's performance & .801 & .312 \\
A13 & Have a strategy of product innovation & .697 & .451 \\
A14 & Evaluate product innovation's performance & .662 & .532 \\
A16 & Evaluate process innovation's performance & .251 & .965 \\
A15 & Have a strategy of process innovation & .321 & .779 \\
\hline
\end{tabular}

All of the primary factor loadings used in the factor interpretation exceeded .50 in value. According to Hair et al. (2010), factor loadings greater than \pm .30 are considered to meet the minimal level; loadings of \pm .40 are considered important; and if the loadings are \pm .50 or greater, they are considered more important.

Considering the factor loadings, the rotated factors are interpreted below and visually displayed in Figure 1.

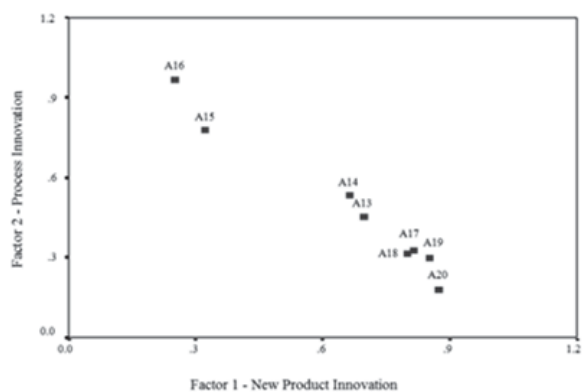

Figure 1: Rotated innovation strategy factor plot

1. New Product Innovation - The Eigenvalue of the first factor was 5.702. The product innovation variables (A13A14), marketing innovation variables (A17-A18) and the management innovation variables (A19-A20), loaded heavily on this factor. Taken together, this pattern of factor loadings clearly reflects the aggressiveness of a company's new product development program in relation to the product, marketing and innovation activities.

2. Process Innovation - The Eigenvalue of the second factor was 1.744. The two process innovation variables (A15-A16) both loaded heavily on this factor. The process innovation variables were selected to measure the emphasis a company places on a stated and working strategy of process innovation and the way it evaluates process innovation's performance relative to objectives. For example, it would measure procedures that are involved in transforming inputs into outputs.

\subsection{Factor analysis: company performance}

The methodology for factor analysing the dependent variables, was similar to that used for the previous sections. The six company performance variables (B31 - B36) were factor-analysed by using the principal axis factoring method. Then, using the latent root criterion, two factors were extracted on the basis of their Eigenvalues being greater than 1. Together they accounted for 75.80 percent of the variation in the data. The factors were rotated by using Varimax rotation method. The same number of methods was used to determine the appropriateness of a factor-analytic model for this analysis.

The correlation matrix for the six company performance variables was reviewed to confirm the existence of a substantial number of correlations, which indicates the existence of common factors. All the variables had correlations greater than .16 and more than 40 percent of the matrix elements were greater than .50. Bartlett's test of sphericity confirmed, that the correlation matrix was not an identity matrix.

The Kaiser-Meyer-Olsen (KMO) measure as sampling adequacy was .791, which Hair et al. (2010) characterised as "middling". This is also defined as an adequate measure, indicating that the degree of correlation between the unique 
factors was low. The anti-image covariance matrix contained no elements with values greater than 0.9 , again confirming the applicability of factor analysis.

Based on the Kaiser criterion of selecting factors with Eigenvalues greater than 1, the number of factors to be extracted, were set at two. However, the scree test indicates, that three factors would be retained. In combining these two criteria, two factors were eventually retained for further analysis, because of the very low Eigenvalue (.538) for the third factor.

The Chi-square statistic was 235.832 with 15 degrees of freedom, which is significant at the .000 level. The reduced set of variables collectively meets the necessary threshold of sampling adequacy and thus the fundamental requirements for factor analysis.

The final statistics showed, that 75.80 percent of the variance was explained by the two factors. The reproduced correlation matrix contained 3 residual values (20 percent) greater than .05 , indicating that the model fits the data. As a reminder, each respondent was asked to respond to the following questions:

B31. Approximately what percentage of sales over the last three years was due to new products?

B32. Approximately what percentage of innovation projects over the last three years earned a profit?

B33. Approximately what percentage of innovations over the last three years could be considered new-to-the-world breakthroughs?

B34. What is your three-year-average R\&D expenditure as a percentage of sales?

B35. What is your three-year-average number of patents registered per year?

B36. What is your company or division's three-year-average ROA?

The rotated company performance factor loadings are contained in Table 2. The heaviest factor loading for each variable is formatted in bold font style. All of the primary factor loadings used in the factor interpretation, exceeded .50 in value.

Table 2. Rotated company performance factor matrix

\begin{tabular}{|clcc|}
\hline Variable & Variable Description & Factor 1 & Factor 2 \\
\hline B32 & Efficiency of innovation project management & .841 & .308 \\
B33 & Impact of the innovations & .797 & .213 \\
B31 & New product contribution to sales & .773 & .188 \\
B34 & R\&D expenditure & .756 & .123 \\
B35 & Patents registered & .089 & .762 \\
B36 & Return on assets & .308 & .619 \\
\hline
\end{tabular}

1. Input Performance - The conceptual definition for this factor is the extent to which the R\&D manager or other top manager perceives the innovation management organisation has achieved its desired objectives over the last three years. The Eigenvalue of the first factor was 3.167. The four input variables (B31 - B34) loaded heavily on this factor. Taken together, this pattern of factor loadings clearly reflects the effectiveness of the innovation management organisation (IMO).

2. Output Performance - This factor represents the performance of the company where (1) patent information was used to measure R\&D activities and (2) return on assets (ROA) was used to measure company financial performance. The Eigenvalue of the second factor was 1.381. The patent's registered variable (B35) and the return on assets variable (B36) loaded heavily on this factor, indicating the degree of fit for this performance measure.

Considering the factor loadings, the rotated factors are interpreted below and visually displayed in Figure 2 .

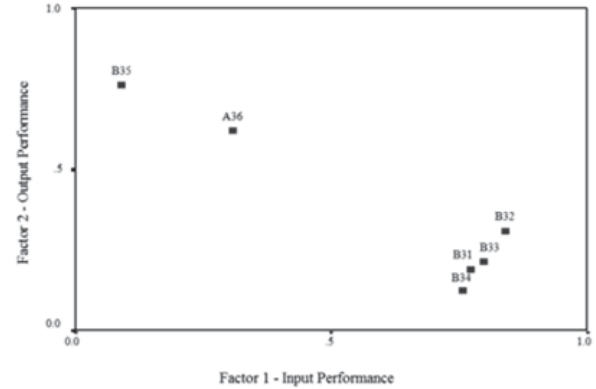

Figure 2: Company performance factor plot 


\subsection{Reliability and validity}

The Cronbach alpha computations for the nine extracted factors are shown in Table 3. For the new product innovation it is .9418; for the process innovation it is .9093 , and for the input performance it is .8887 . These high values indicate a high degree of data stability.

Table 3. Reliability analysis

\begin{tabular}{|c|c|c|c|c|c|}
\hline Variable & $\begin{array}{l}\text { Scale mean if } \\
\text { item deleted }\end{array}$ & Scale variance if item deleted & $\begin{array}{l}\text { Corrected item } \\
\text { total correlation }\end{array}$ & Alpha if item deleted & Alpha \\
\hline \multicolumn{6}{|c|}{ New Product Innovation (NPI) } \\
\hline A13 & 15.6786 & 28.8713 & .7994 & .9343 & \multirow{6}{*}{.9418} \\
\hline A14 & 15.9167 & 28.7761 & .7888 & .9353 & \\
\hline A17 & 15.8690 & 27.8501 & .8486 & .9283 & \\
\hline A18 & 16.0714 & 27.3924 & .8301 & .9302 & \\
\hline A19 & 16.0000 & 25.8313 & .8620 & .9268 & \\
\hline A20 & 15.9405 & 26.3940 & .8350 & .9301 & \\
\hline \multicolumn{6}{|c|}{ Process Innovation (PI) } \\
\hline A15 & 3.1429 & .6299 & .8503 & - & \multirow{2}{*}{.9093} \\
\hline A16 & 3.3095 & .9392 & .8503 & - & \\
\hline \multicolumn{6}{|c|}{ Input Performance (InP) } \\
\hline B31 & 6.9405 & 13.3820 & .7446 & .8617 & \multirow{4}{*}{.8887} \\
\hline B32 & 7.1429 & 13.0637 & .8234 & .8305 & \\
\hline B33 & 7.6548 & 13.1685 & .7540 & .8584 & \\
\hline B34 & 7.8333 & 15.1044 & .7130 & .8741 & \\
\hline \multicolumn{6}{|c|}{ Output Performance (OutP) } \\
\hline B35 & 21.2381 & 151.9185 & .5015 & - & \multirow{2}{*}{.4104} \\
\hline B36 & 2.4524 & 11.6724 & .5015 & - & \\
\hline
\end{tabular}

Looking at Table 3, it is evident that the output performance factor coefficient alpha is only .4104. However, the data accuracy aspect of reliability can be tested by comparing the test data with external criteria that measure the same variable. In this study the self-reported company return on asset variable (B36) was compared with published financial data from various sources (I-Net Bridge, company reports, etc.). Sixty-seven of 84 respondents correctly reported the return on asset (ROA) category. Fourteen cases exaggerated their ROA by one category and the remaining three cases diminished their ROA by one category. Three Chi-square-based measures of association were calculated, i.e. the phi coefficient, the coefficient of contingency and Cramer's V. Their respective values were 1.26, .63 and .78. All were significant at the .00000 level (rounded to the fifth decimal place), indicating a strong relation between the reported and actual ROA data. These factors point to an acceptably high degree of data reliability.

\subsection{Multiple regression analysis}

To ascertain the relative importance of the factors in explaining the variation in the dependent variables, multiple regression analysis was used to analyse the relationship between the dependent variables and independent variables. The objective of multiple regression analysis, is to use the independent variables (two factors) whose values are known to predict the single dependent values (two performance factors). The Pearson r-correlations were calculated to find the strength and direction of the relationships between the factors and the performance dimensions. By using $p$-values, it was possible to distinguish between the levels of significance. It is apparent from Table 4 that the New Product Innovation factor has a significant positive effect on Input Performance $(p<0.01)$. From Table 4 it can be seen that both nullhypothesis was rejected $(p<0.01)$ for the two innovation strategy dimensions. 
Table 4. Correlation matrix

\begin{tabular}{|c|c|c|c|c|c|}
\hline & & New Product Innovation & Process Innovation & Input Performance & Output Performance \\
\hline $\begin{array}{l}\text { New Product } \\
\text { Innovation }\end{array}$ & $\begin{array}{l}\text { Pearson Correlation } \\
\text { Sig. (2-tailed) } \\
\mathrm{N}\end{array}$ & $\begin{array}{c}1.000 \\
84\end{array}$ & \begin{tabular}{|c|}
$.614^{\star}$ \\
.000 \\
84 \\
\end{tabular} & \begin{tabular}{|c|}
$.684^{\star}$ \\
.000 \\
84 \\
\end{tabular} & \begin{tabular}{|c|}
$.296^{\star}$ \\
.000 \\
84 \\
\end{tabular} \\
\hline $\begin{array}{l}\text { Process } \\
\text { Innovation }\end{array}$ & $\begin{array}{l}\text { Pearson Correlation } \\
\text { Sig. (2-tailed) } \\
\mathrm{N}\end{array}$ & $\begin{array}{c}.614^{*} \\
.000 \\
84 \\
\end{array}$ & $\begin{array}{c}1.000 \\
84\end{array}$ & $\begin{array}{c}.467^{\star} \\
.000 \\
84 \\
\end{array}$ & $\begin{array}{l}.175 \\
.111 \\
84 \\
\end{array}$ \\
\hline $\begin{array}{l}\text { Input } \\
\text { Performance }\end{array}$ & $\begin{array}{l}\text { Pearson Correlation } \\
\text { Sig. (2-tailed) } \\
\mathrm{N}\end{array}$ & $\begin{array}{c}.684^{*} \\
.000 \\
84\end{array}$ & $\begin{array}{c}.467^{\star} \\
.000 \\
84\end{array}$ & $\begin{array}{c}1.000 \\
84\end{array}$ & $\begin{array}{c}.435^{\star} \\
.000 \\
84\end{array}$ \\
\hline $\begin{array}{l}\text { Output } \\
\text { Performance }\end{array}$ & $\begin{array}{l}\text { Pearson Correlation } \\
\text { Sig. (2-tailed) } \\
\mathrm{N}\end{array}$ & $\begin{array}{l}.296^{\star} \\
.006 \\
84\end{array}$ & $\begin{array}{l}.175 \\
.111 \\
84\end{array}$ & $\begin{array}{l}.435^{\star} \\
.000 \\
84\end{array}$ & $\begin{array}{c}1.000 \\
84\end{array}$ \\
\hline
\end{tabular}

*. Correlation is significant at the 0.01 level (2-tailed).

The level of relationship ( $\mathrm{R}^{2}$ or $\mathrm{Rsq}$ ) that can be detected reliably with the proposed regression analysis was calculated to indicate the percentage of total variation of the Input Performance factor (InP). The New Product Innovation factor (Rsq = 0.4676) explains $47 \%$ of the total variation of the Input Performance factor. It implies that the aggressiveness of a company's new product development program in relation to the product, marketing and innovation activities determine the variation of the company's contribution to sales, efficiency of innovation project management, impact of the innovations and research and development expenditure. The Process Innovation factor (Rsq $=0.2182$ ) explains $22 \%$ of the total variation of the Input Performance factor. It signifies, that the emphasis a company places on a stated and working strategy of process innovation and the way it evaluates process innovation's performance, relative to objectives, determine the variation of the company's contribution to sales, efficiency of innovation project management, impact of the innovations and R\&D expenditure.

The level of relationship ( $\mathrm{R}^{2}$ or $\mathrm{Rsq}$ ) that can be detected reliably with the proposed regression analysis was calculated for the creation of the Output Performance factor (OutP). The New Product Innovation factor (Rsq $=0.0874$ ) explains $9 \%$ of the total variation of the Output Performance factor. It signifies, that the aggressiveness of a company's new product development program in relation to the product, marketing and innovation activities determines the variation of the company's contribution to R\&D activities (patents registered) and the company's efficiency in using its assets (return on assets). The Process Innovation factor (Rsq $=0.0307$ ) explains $3 \%$ of the total variation of the Output Performance factor. It signifies, that the emphasis a company places on a stated and working strategy of process innovation, and the way it evaluates process innovation's performance relative to objectives determine the variation of the company's contribution to R\&D activities (patents registered), and the company's efficiency in using its assets (return on assets).

\section{Recommendations}

The New Product Innovation factor explains 47 percent of the total variation of the Input Performance factor. This means that a strong market orientation, marketing proficiency and a clear product definition, have all been found to be positively correlated with company performance. The New Product Innovation factor also explains 9 percent of the total variation of the Output Performance factor. It signifies, that the aggressiveness of a company's new product development program in relation to the product, marketing and innovation activities, determines the variation of the company's contribution to R\&D activities and the company's efficiency in using its assets.

The Process Innovation factor explains 22 percent of the total variation of the Input Performance factor. It signifies, that the emphasis a company places on a stated and working strategy of process innovation and the way it evaluates process innovation's performance, relative to objectives, determine the variation of the company's contribution to sales, efficiency of innovation project management, impact of the innovations and R\&D expenditure. The Process Innovation factor also explains 3 percent of the total variation of the Output Performance factor. It signifies, that the emphasis a company places on a stated and working strategy of process innovation, and the way it evaluates process innovation's performance relative to objectives, determine the variation of the company's contribution to R\&D activities, and the company's efficiency in using its assets.

It is recommended that companies use innovation proactively as a competitive weapon and a key-positioning 
factor. Furthermore, that these companies should accept technical risk, increasing the sophistication of innovation components utilised and the number of innovations in which the company maintains competence.

\section{Conclusion}

Strategic management is inter alia a process of managing a company's relationship with the environment. A critical concern of this discipline is optimising returns to the company's stakeholders over the long term. This means sustaining performance by balancing strategic investments in innovation with short-term profitability.

The present study makes a contribution to the field of strategic management research by integrating the dimensions of several previous studies, to derive a more comprehensive taxonomy of innovation strategy dimensions. It also derives a broader set of dimensions for use in strategic management research. The results show that innovation strategy choices can significantly affect company performance. It thereby indicates which of the underlying dimensions have the strongest relationship with company performance.

\section{References}

Brush, C.G. \& Vanderwerf, P.A. (1992). A comparison of methods and sources for obtaining estimates of new venture performance. Journal of Business Venturing, 7(2), 157-170.

Dahan, G. \& Shoham, A. (2014). Strategic orientations: developing an integrative model of pioneering, entrepreneurial, and stakeholder orientations. Procedia - Social and Behavioral Sciences, 109, 758-762.

Ensminger, D.C., Surry, D.W., Porter, B.E., \& Wright, D. (2004). Factors Contributing to the Successful Implementation of Technology Innovations. Educational Technology \& Society, 7(3), 61-72.

Freeman, C. (1994). The economics of technical change. Cambridge Journal of Economics, 18(5), 463-514.

Garnett, A. \& Pelser, T.G. (2007). Organisational barriers to creativity in South African higher education institutions. South African Journal of Higher Education, 21(1), 50-67.

Hair, J.F. JNR, Black, W.C, Babin, B.J \& Anderson, R.E. (2010). Multivariate data analysis: a global perspective. 7th ed. Upper Saddle River: Pearson Prentice Hall.

Hansen, A. (2010). Nonfinancial performance measures, externalities and target setting: a comparative case study of resolutions through planning. Management Accounting Research, 21(1), 17-39.

Hamel, G. \& Prahalad, C.K. (2006). The core competence of the corporation strategic learning in a knowledge economy. (In Hahn, D. \& Taylor, B., eds. Strategische Unternehmungsplanung - Strategische Unternehmungsführung.) Berlin, Heidelberg: Springer.

Harmon, P. \& Davenport, T. (2007). Business process change. 2nd ed. Burlington, Massachusetts: Morgan Kaufmann.

Hung-Chia, S.H. (2013). Technology timing of IPOs and venture capital incubation. Journal of Corporate Finance, 19(1), 36-55.

Levitt, T. (1983). The globalisation of markets. Harvard Business Review, 61(3), 92-102.

Murphy, G.B., Trailer, J.M. \& Hill, R.C. (1996). Measuring performance in entrepreneurship research. Journal of Business Research, $36(1), 15-23$.

Ohmae, K. (1989). Managing in a borderless world. Harvard Business Review, 67(3), 152-161.

Panagiotou, G. (2007). Reference theory: strategic groups and competitive benchmarking. Management Decision, 45(10), 1595-1621.

Pandian, J.R, Thomas, H. Furrer, O. \& Bogner, W.C. (2006). Performance differences across strategic groups: an examination of financial market-based performance measures. Strategic Change, 15(6), 373-383.

Pérez-Luño, A. \& Cambra, J. (2013) Listen to the market: do its complexity and signals make companies more innovative? Technovation, 33(6/7), 180-192.

Pérez-Luñoa, A., Wiklundb, J. \& Cabrera, R.A. (2011). The dual nature of innovative activity: how entrepreneurial orientation influences innovation generation and adoption. Journal of Business Venturing, 26(5), 555-571.

Pelser, T.G. (2001). A strategic management taxonomy of technology and innovation. Unpublished PhD thesis. Potchefstroom: Potchefstroomse Universiteit vir Christelike Hoër Onderwys.

Rauch, A., Wiklund, J., Freese, M. \& Lumpkin, T. (2009). Entrepreneurial orientation and business performance: cumulative empirical evidence. Entrepreneurship Theory and Practice, 33(3), 761-779.

Rothwell, R. (1992). Successful industrial innovation: critical factors for the 1990s. R\&D Management, 22(3), 221-239.

Shoham, A. \& Fiegenbaum, A. (2002), Competitive determinants of organisational risk-taking attitude: the role of strategic reference points. Management Decision, 40(2), 127-141.

Song, M., Zhao, Y.L. \& Di Benedetto, C.A. (2013). Do perceived pioneering advantages lead to first-mover decisions? Journal of Business Research, 66(8), 1143-1152.

Zahra, S.A. \& Hayton, J.C. (2008). The Effect of international venturing on firm performance: the moderating influence of absorptive capacity. Journal of Business Venturing. 23(2), 195-220. 